\title{
Clinical Observations Character Result in Standard Format
}

National Cancer Institute

\section{Source}

National Cancer Institute. Clinical Observations Character Result in Standard Format. NCI Thesaurus. Code C119813.

The standard character or string for representation and reporting of clinical observations data. 